\title{
Hereditary sensory and autonomic neuropathy type 3 in non-Jewish child
}

\author{
Neuropatia hereditária sensitivo-motora tipo 3 em uma criança não judia \\ Ana Ligia da Silva Silveira', Raquel Trautenmüller Kerber Binkowski², Bruna Feltrin Rich³, Marilian Bastiani \\ Benetti ${ }^{3}$, Adriana Maria de Almeida ${ }^{4}$
}

\begin{abstract}
Department of Pediatric Neurology, Hospital Universitário de Santa Maria, Santa Maria RS, Brazil.
${ }^{1}$ Pediatric Neurologist at Hospital Universitário de Santa Maria, Santa Maria RS, Brazil;

${ }^{2}$ Resident of Pediatrics Neurology at Hospital Universitário de Santa Maria, Santa Maria RS, Brazil;

${ }^{3}$ Resident of Pediatrics at Hospital Universitário de Santa Maria, Santa Maria RS, Brazil;

4Medicine Graduation student, Faculdade de Medicina do Hospital Universitário de Santa Maria, Santa Maria RS, Brazil.

Correspondence: Ana Lígia da Silva Silveira;Avenida Roraima / prédio 22; 97105-900 Santa Maria RS - Brazil; Email: rtkerber@yahoo.com.br Conflict of interest: There is no conflict of interest to declare.

Received 25 April 2012; Received in final form 15 May 2012; Accepted 23 May 2012
\end{abstract}

Hereditary sensory and autonomic neuropathy type 3 (HSAN3), also known as familial dysautonomia or Riley Day syndrome, is an rare hereditary autosomal recessive anomaly characterized by impairment of sensory and sympathetic innervation. The prevalence is $1: 10,000$ to $1: 20,000$ Ashkenazi Jews newborns. This condition is considered a rare condition among non-Jewish children ${ }^{1-3}$.

\section{CASE REPORT}

The patient was a 16 year-old girl, who presented no complications at birth and had no known disease in her family. Her parents were not consanguineous and had no-Jewish ancestry.

When she was two months old, she started presenting bronchial hyper reactivity, pneumonias, chronic diarrhea, and malnutrition that took her to several hospitalizations. By 11 months old, she started presenting an irritable behavior and episodes of self-harm, when she would bite her lips, tongue,

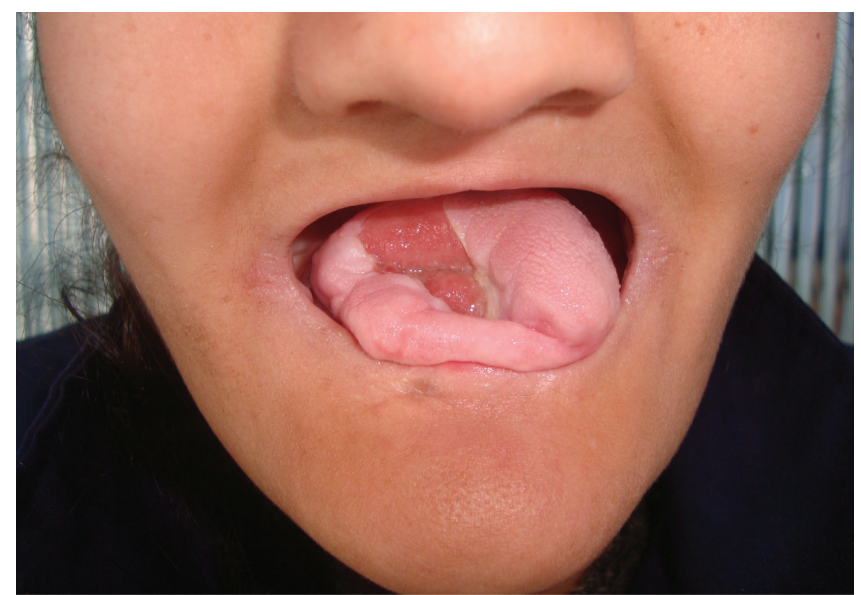

Fig 1. Smooth tongue, presenting a tongue scar and mandibular protrusion. hands and feet, which left permanent scars on these places (Fig 1). In order to stop the self-caused injuries, her teeth had to be removed. At that time she was noted to present generalized hypotonia and developmental delay; she was found to show no perception of pain or miotact reflexes.

From three to six years old, she went through many hospital admissions due to distal phalanges osteomyelitis (caused by herself-mutilation) and/or recurrent bone fractures (caused by frequent falls). In one admission, burn scars on the trunk and limbs where also noted which brought up the hypothesis that the patient would present no tactile and thermal sensitivity.

At eight years old, she started presenting some orthopedic changes (kyphoscoliosis and mandibular protrusion).

Currently, she presents a mild cognitive impairment, hypotonia, abolition of miotatic reflexes, global analgesia, absence of tactile and pain sensitivity. Besides, she presents with short stature, postural hypotension, decreased tear volume, absence of fungiform papillae on the tongue, chronic diarrhea, and acrodystrophy in hands (Fig 2) and feet.

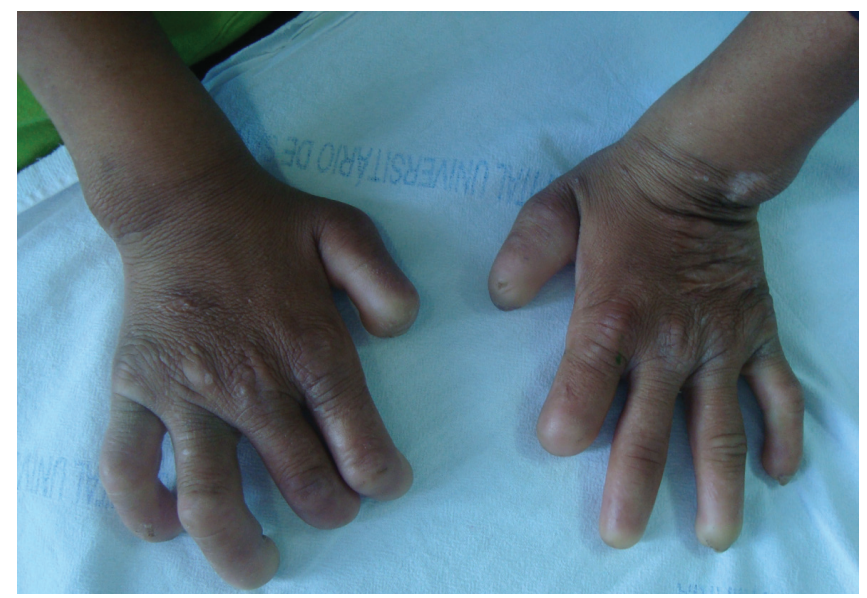

Fig 2. Acrodystrophy in hands. 
She had undergone an electromyography, which showed reduced motor conduction velocity, reduced compound motor action potential amplitudes and absent sensory nerve action potentials.

\section{DISCUSSION}

This disorder is a progressive sensorimotor neuropathy. The sympathetic autonomic dysfunction is considered the cause of the majority of the clinical manifestations ${ }^{4,5}$ :

- Episodes of dysautonomic crises, characterized by nausea, vomiting and symptoms of sympathetic storm (irritability, tachycardia, hypertension, facial flushing, bronchorrhea and diminished oral coordination leading to swallowing and speech dysfunction);

- Additional autonomic symptoms include orthostatic hypotension, excessive salivation, gastrointestinal motility dysfunction, bladder dysfunction, decreased or absent tearing, pupil dilation, hypohidrosis, episodic hyperhidrosis and blotchy skin;

- Glomerulo sclerosis and chronic kidney disease unrelated to autonomic dysfunction;

- Neuropathic symptoms: loss of reflexes, hypotonia, decreased perception of pain and temperature;

- Additional clinical features: short stature, kyphoscoliosis, smooth tongue (no fungiform papillae), vomiting, recurrent aspiration, multiple skin scars, dysarthria, mental deficiencies, and emotional lability.

Linkage studies map to a candidate region on chromosome 9q31. Genetic evaluation is considered sensitive and specific for the diagnosis of HSAN3. Furthermore, it's the only specific diagnostic test currently available.

No particular treatment for familial dysautonomia has yet been described. Supportive care and symptomatic therapies are the main stay of management. The prognosis is poor.

\title{
References
}

1. Klebanoff MA, Neff JM. Familial dysautonomia associated with recurrent osteomyelitis in a non-Jewish girl. J Pediatr 1980; 96:75-77.

2. Levine SL, Manniello RL, Farrell PM. Familial dysautonomia: unusua presentation in an infant of non-Jewish ancestry. J Pediatr 1977; 90:79-81.

\footnotetext{
3. Mehta K. Familial dysautonomia in a Hindu boy. Am J Dis Child 1978;132:719.

4. Riley CM, Day RL. Central autonomic dysfunction with defective lacrimation; report of five cases. Pediatrics 1949;3:468-78.

5. Axelrod FB. Familial dysautonomia. Muscle Nerve 2004; 29:352-363.
}

\section{Subcostal schwannoma in pregnancy}

\section{Schwannoma subcostal na gravidez}

\author{
Júverson Alves Terra Júnior'1, Edmilson Rodrigo Daneze², Guilherme Azevedo Terra ${ }^{3}$, \\ Renata Margarida Etchebehere ${ }^{4}$, Aldo Benjamim Rodrigues Barbosa ${ }^{5}$, Silvia Azevedo Terra6*
}

${ }^{1}$ MD, Professor of Surgery, Department of Surgery, Federal University of Triângulo Mineiro (UFTM), Uberaba MG, Brazil;

${ }^{2}$ Veterinarian, Faculdade Doutor Francisco Maeda (FAFRAM/FE), Ituverava SP, Brazil;

${ }^{3}$ Medical Student, Department of Surgery, Federal University of Triângulo Mineiro (UFTM), Uberaba MG, Brazil;

${ }^{4} \mathrm{PhD}$, Professor of Pathology, Department of Pathology, Federal University of Triângulo Mineiro (UFTM), Uberaba MG, Brazil;

${ }^{5} \mathrm{MD}$, Radiologist, Department of Radiology. Santa Casa de Misericórdia de Ituverava, Ituverava SP, Brazil;

${ }^{6} \mathrm{PhD}$, Professor of Pathology, Department of Pathology, Federal University of Triângulo Mineiro (UFTM), Uberaba MG, Brazil.

*in memoriam.

Correspondence: Júverson Alves Terra Júnior; Department of Surgery, Federal University of Triângulo Mineiro (UFTM); Avenida Frei Paulino 30; $38025-180$ Uberaba MG - Brasil;E-mail: juverson@terra.com.br

Conflict of interest: There is no conflict of interest to declare.

Received 04 May 2012; Received in final form 11 May 2012; Accepted 18 May 2012

The schwannoma is a supporting cells tumor of peripheral nervous system, characterized by the formation of grayish, firm, circumscribed and usually solitary masses, which is located close to the roots of cranial and spinal nerves. Most of them have a benign character ${ }^{1}$.

\section{CASE REPORT}

A 27-year-old Caucasian female, with pregnancy at term, who was subjected to routine ultrasound, which observed the presence of hyperechoic lesion at the left hypochondrium 